\title{
Roman Baths: An Alternate Mode of Viewing the Evidence
}

Tanya Henderson, University of Alberta

Roman baths are an important component in furthering our knowledge of Roman social life. They functioned as more than just a locus for cleansing the body. Currently, the literary sources provide the most details about the various social activities that occurred in the baths. However, where these activities took place within the complexes remains unclear. Archaeological reports do not adequately address how the rooms functioned. The argument presented here outlines some of the problems with the current methodology for examining room function in room baths. Then, using the site of Hammat Gader in Israel, introduces a different mode of viewing the evidence.

The activities that occurred in Roman baths are significant in understanding Roman social life. The baths were the setting for more than just cleansing the body and a variety of ball games, wrestling, eating and other social activities took place within the baths. ${ }^{1}$ Literary sources, such as Pliny the Younger, Martial and Juvenal, all provide us with accounts of life at the baths. ${ }^{2}$ Yet, while there is an abun-

\footnotetext{
${ }^{1}$ For ball games see: Petronius, Sat., 27; Mart., Epig. 14.47 and 7.32. For wrestling see Juv., 6.422-423. For eating see Sen., Ep. 56.2.

${ }^{2}$ For a complete list of literary sources that mention the baths and to realize the sheer volume of literary evidence see I. Nielsen, Thermae et Balnea (Aarhus, Den-

Past Imperfect

13 (2007) | @ | ISSN 1192-1315
} 
dance of literary evidence that provides a general idea as to what these activities were, it is still unclear as to where these activities took place within the bath complex. These sources also focus on the elite in Rome and do not inform about practices in other parts of the empire, such as North Africa, the western provinces or the eastern provinces.

Analyses using the physical evidence, which can provide information on the function of various rooms within the complex, tend to focus on the specialized features of the baths, such as the hypocaust system to determine room function based on the relative position of the rooms to a heat source. They do not examine the artefact assemblage. Once labels, such as caldarium, tepidarium, and frigidarium are applied, based on the rooms' location with respect to the primary source of heat for heating the baths, room function is assumed and not explored further. These labels do not offer an adequate representation of what activities took place within these rooms but presume that the application of ancient terminology is sufficient to explain how the rooms functioned. One of the problems with applying ancient terminology is that our current understanding of these terms is not equivalent to the ancient Roman's concept of these terms. Caution must be applied when using these terms and a clear description of what these terms constitutes delineated in order to facilitate a modern conception of these terms in respect to room function.

In order to arrive at a better understanding of how the baths were used I propose to outline an alternate mode of viewing the material evidence that will take into consideration more than just the architecture to provide a more complete understanding of the social

mark: Aarhus University Press, 1990), I:195-203 and G.G. Fagan, Bathing in Public in the Roman World (Ann Arbor: University of Michigan Press, 1999), 413-430.

Past Imperfect

13 (2007) | @ | ISSN 1192-1315 
activities that took place in Roman baths. I have chosen the site of Hammat Gader, in Israel, as the case study for my argument. The excavation report on Hammat Gader, excavated by a team of archaeologists supervised by Yizhar Hirschfeld includes the artefact assemblage with provenance of finds recorded by rooms. Unfortunately, there is no comparative data with which to compare the site, as many bath publications do not include the artefact assemblages and instead focus on the architecture. The purpose of this study is to challenge scholars in the field to look at the physical evidence, rather than the literature to determine what activities took place in the baths. The choice of Hammat Gader, a site far from Rome and in a periphery province that did not easily succumb to the trappings of Roman culture, provides an excellent opportunity to determine if there were any regional variations in the use of bath complexes across the Roman empire. What would further facilitate this study is the existence of a similar study of baths in Rome itself, as such a study does not currently exist, the premise behind my argument will be that the literary accounts, focused on Rome, provide an accurate representation of the bathing culture in Rome. I will examine the physical evidence from Hammat Gader to see if there are any similarities or differences in the use of the structure as compared to a socalled "typical" Roman bath.

First, how room function is currently approached in baths in the Roman world will be summarized with specific attention to how the archaeological evidence is used to assign labels to the various rooms. What is the process by which the various activities that occurred within the baths get assigned to specific rooms in the complex? Is there a process? Defining this process is a crucial component of the study presented here. Is the current approach adequate to answer specific questions, such as was the consumption of food limited 
to certain areas or were there only certain rooms in which the patrons could apply special oils and unguents? Is more than one approach used to determine room function? What are the limitations of these approaches? Once these questions have been addressed I will apply a new mode of viewing the evidence, using the bath complex at Hammat Gader as an example. I hope that this will add to the current understanding of room function in Roman baths.

There are two types of evidence used to determine room function in Roman baths: the ancient sources, which include both literary works and epigraphic material; and the material remains, which include the architecture, decoration and artefact assemblages. The literary evidence receives more consideration than the archaeological evidence in determining what activities occurred in the baths. ${ }^{3}$ Therefore, I will address the literary evidence first.

\section{The Literary Evidence}

The literary evidence provides information not possible to arrive at from the physical remains of the structures themselves. Authors such as Martial, Seneca and Pliny the Younger as well as graffiti allow us glimpses not only of daily habits in the baths, but also of some of the more sinister elements associated with the baths such as violence, prostitution and over indulgence in food and drink. ${ }^{4}$ Our concept of the standard bathing routine developed from the sources. This is the all too familiar traditional order described in a number of handbooks

\footnotetext{
${ }^{3}$ See for example Fagan, Bathing in Public, 12-39. Fagan relies only upon the literary evidence to answer the sociohistorical questions he raises, see Fagan, Bathing in Public, 10.

${ }^{4}$ On violence see Pliny, Ep. 3.14. For prostitution see CIL 4.10675, 4.10676, 4.10677 and 4.10678. For over indulgence of food see Mart., Epig. 12.19. For drunken behaviour see Mart., Epig. 12.70; Sen., Ep.122.6; Pliny, NH. 14.139; and Quint., Inst. 1.6.44.
}

Past Imperfect 
on Roman daily and social life. ${ }^{5}$ First, the bather works up a sweat either by exercising or by sitting in one of the hot steam rooms. Then, an oil is applied and strigilled off. Finally, the bather takes a dip in a cold-water pool to tone the body, finishing off the bathing experience. ${ }^{6}$ Although the literary sources mention a number of different activities that occurred within the baths ${ }^{7}$ these do not factor into the custom of bathing but remain subsidiary to the abovementioned routine. Indeed, it is only J. Carcopino, who cites an alternate Lacedaemonian bathing routine mentioned but not described by Martial. ${ }^{8}$

Medical authors, such as Celsus and Galen, suggest various therapeutic hydrotherapies that also do not follow the 'traditional' order of bathing. ${ }^{9}$ Are these other routines not a part of the whole experience? Are the subsidiary activities, such as ball games, eating, drinking and fornicating not a part of the experience? Would the performance of these activities obstruct the regular sequence of bathing? Where did these activities occur? At any point in time, there could be any number of patrons utilizing the baths in any number of ways. Yet no study addresses the flow and movement of the people in the baths. Studies on the experience of the bathers remove the bathers from the

\footnotetext{
${ }^{5}$ See for example J. Carcopino, Daily Life in Ancient Rome, trans. E. O. Lorimer (New Haven: Yale University Press, 1940) 260-1; J.P.V.D. Balsdon, Life and Leisure in Ancient Rome (New York: McGraw-Hill Book Company, 1969), 29; and F. Dupont, Daily Life in Ancient Rome, trans. C. Woodall (Oxford: Blackwell, 1992), 264. In which, only Carcopino cites Martial as evidence for alternate bathing routes, see Mart., Epig. 5.42.

${ }^{6}$ This traditional method of bathing developed from the following sources: Pliny, NH 28.55; Petronius, Sat. 28; and Mart., Epig. 5.42.

${ }^{7}$ See for example, Lib., Or. 3.6.16 on rooms for lectures, poetry reading and music. Numerous sources discuss eating in the baths; Mart., Epig. 5.70 and 12.19; Sen., Ep. 56.2. Drinking: Mart., Epig. 12.70; Pliny, HN. 14.139. Prostitution: Mart., Epig. 3.93.14; Luccian, Hipp. 5.

${ }^{8}$ Mart., Epig. 5.42.

${ }^{9}$ See for example Celsus, 2.17.1-10, 3.6.13-14, 3.12.3-4 and for Galen particularly De Sanitate Tuenda 6.1-452. These are only a selection of the references made by these two particular authors.
} 
physical location of the baths and rely heavily upon the literary sources. ${ }^{10}$ These studies do not attempt to integrate the two types of evidence.

Although the literary evidence provides invaluable information, there are also problems with using it. First, not only are the sources chronologically and geographically diverse, but so are the baths to which the literary evidence is applied. Second, an over reliance on the literary sources does not account for changes in the bathing practice over time and place. Questions such as, who is the author, who is the audience, when and where were the text written all need consideration. If the literary evidence used to explain the physical evidence applies to a different place and time, can it be applied with any certainty?

\section{The Archaeological Evidence}

The archaeological evidence focuses on the design of Roman baths, specifically where the rooms are in relation to the hypocaust system, to determine room function. ${ }^{11}$ Andrew Farrington has conducted a thorough survey of baths in the imperial period in Lycia. He includes a section called Lycian Bathing Habits in which he hypothesizes, based on the archaeological evidence, how the baths in Lycia may have been used. ${ }^{12}$ Farrington specifically uses the term room function, which suggests a detailed analysis of the evidence to arrive at

\footnotetext{
${ }^{10}$ See for example G. G. Fagan, "Interpreting the Evidence: Did Slaves Bathe at the Baths?" in Roman Baths and Bathing edited by J. DeLaine and D. E. Johnston (Portsmouth: Journal of Roman Archaeology, 1999), vol. 1:23-34. (Henceforth, this body of work will be referred to as Roman Baths vol. 1 or vol. 2).

${ }^{11}$ For constraints of space, the argument will focus on one particular excavation report with reference to others, but this study is admittedly not inclusive of all the evidence.

${ }^{12}$ Andrew Farrington, The Roman Baths of Lycia: An Architectural Study (Ankara: British Institute of Archaeology at Ankara, 1995), 7-15. 
his conclusions. He begins with a general description of the bathing practice, reciting what the handbooks referred to above inform, and cites neither archaeological nor literary evidence to support this description. ${ }^{13} \mathrm{He}$ does admit that variations in the bathing sequence could have been numerous, but he takes a defeatist position and claims that "very little, beyond obvious archaeological deductions, helps us divine the precise functions of the innumerable rooms in large bath complexes." 14 So, what are his "obvious archaeological deductions"?

Farrington begins by applying labels to the rooms based on their relative nearness to or distance from the praefurnium, the furnace to heat the baths. He uses the standard labels of caldarium, tepidarium, and frigidarium. ${ }^{15}$ Farrington focuses more on the layout of the baths, using Krencker's 1929 standard typology. ${ }^{16}$ His one exception to this method is in discussing the heliocaminus, a room for sun tanning, for which he uses specific architectural features such as windows and arches in walls to identify room function. ${ }^{17}$ There is no mention of the artefact assemblage.

Other studies that consider room function include Inge Nielsen's two-volume study on the architectural and cultural history of baths in the Roman world that includes an appendix on individual elements of the baths. ${ }^{18}$ All the elements are analysed according to

\footnotetext{
${ }^{13}$ Ibid., 8 .

${ }^{14}$ Ibid., 8.

${ }^{15}$ Farrington identifies the most south eastern room in the baths at Nisa using this methodology. Farrington, The Roman Baths of Lycia, 8.

${ }^{16}$ Ibid., 10. Krenker's 1929 typology is the standard typology used to describe the layout of Roman baths. See D. Krencker, Die Trierer Kaiserthermen (Augsburg: B. Filser, 1929)

${ }^{17}$ Farrington, The Roman Baths of Lycia, 12. He applies this method for room 3 in the Central Baths at Patara, which had both a window and open arch in the west wall as well as for room 3 in the North Baths at Patara, which had a window in the west wall.

${ }^{18}$ See Nielsen, Thermae et Balnea, 1:153-166.
} 
their etymology, architecture, function and origin. ${ }^{19}$ A reading of this appendix highlights how unclear the identification and function of many of the rooms are. The ancient terminology, garnered from the literary sources, is used. Labels such as unctorium, heliocaminus, sphaeristerium, and destrictarium all suggest a room with a specific function yet very few of these are identified with any certainty in the archaeological record. Regarding the unctorium, a room for anointing, Nielsen only cites one archaeologically identifiable one from the villa of Piazza Armerina. A mosaic floor depicting anointing is the reason for this identification. ${ }^{20}$

The process of assigning function to rooms in Roman baths is not clear in the current literature. The prevailing trend is to rely upon either the literary evidence or the archaeological evidence; specifically how near or far a room is from the praefurnium and other architectural features, such as windows and arches in walls to identify the heliocaminus. The current approach is not adequate to answer questions more demanding of the evidence and calls for the application of new methodologies.

The field of domestic architecture applied new methodologies for examining artefact assemblages to explain room function. Penelope Allison's work at Pompeii has led to a greater understanding of the fluidity of room function in the Roman house. ${ }^{21}$ The

\footnotetext{
${ }^{19}$ Ibid., 1: 153 .

${ }^{20}$ Ibid., 1: 161.

${ }^{21}$ See for example P. M. Allison, Pompeian Households: An Analysis of the Material Culture, ed. Jeanne E. Arnold et al., Costen Institute of Archaeology, University of California, Los Angeles Monograph 42 (Los Angeles: University of California, 2004). and P. M. Allison, "How Do We Identify the Use of Space in Roman Housing," in Functional and Spatial Analysis of Wall Painting, ed. E. M. Moorman (Leiden: Babesh, 1993), 1-8; and P. M. Allison, "Artefact Distribution and Spatial Function in Pompeian Houses," in The Roman Family in Italy: Status, Sentiment, Space, ed. B. Rawson and P. Weaver (Oxford: Claredon, 1997), 321-354. Note that there is one excavation report on a Roman bath that does take into consideration the artefacts, specifically those recovered from the frigidarium drain. See J. David Zien-
} 
premise behind Allison's work is that the artefact assemblage can provide more information on the actual function of the rooms and a better understanding of the daily activities that occurred in the Roman house. Allison created a database of Pompeian household content by room and then analysed the various spaces to determine what activities occurred based on the artefact assemblage. ${ }^{22}$ Would it be unreasonable to presume that a culture that had such varied uses of space within the domestic sphere also did so in the public sphere? Many of the issues dealt with by scholars in domestic architecture apply to Roman baths. There is an over reliance on the literary evidence to determine room function. When the architecture is used, standard typologies are applied and little consideration given to geographical and temporal differences of the studied sites.

The purpose of conducting this analysis is to demonstrate that there are alternative ways of determining room function in Roman baths that are not solely dependent upon examining the architectural remains. The specialized architecture of baths may indicate what the intended primary function of a room at the time of construction was. The artefact assemblage, however, can reveal the lived reality of how the room functioned. There could be a number of secondary or even tertiary functional uses for a room, which is only evident when semi-permanent settings are present. ${ }^{23}$

The decision to use the bath complex at Hammat Gader for the present study is because the excavation report includes a summary of small finds, such as pottery, coins, oil lamps, glass, marble

kiewicz, The Legionary Fortress Baths at Caerleon II: The Finds (Cardiff: National Museum of Wales, 1986), 17-21 for the discussion based on these finds. ${ }^{22}$ See Allison, Pompeian Households.

${ }^{23}$ Amos Rapoport, "Systems of Activities and Systems of Settings," in Domestic Architecture and the Use of Space: An Interdisciplinary Cross-Cultural Study, ed. Susan Kent, New Directions in Archaeology (Cambridge: Cambridge University Press, 1990), 11-13. 
decoration and wall mosaics and includes their locus. ${ }^{24}$ This analysis does not presuppose to be all-inclusive or representative of all baths in the Roman world. It is, however, an attempt to demonstrate how applying alternate modes of viewing the evidence can lead to a greater understanding of Roman social life at the baths.

\section{The site of Hammat Gader}

The Roman baths of Hammat Gader are located along the Yarmuk River, which separates the state of Israel from Jordan. ${ }^{25}$ The baths were part of the ancient city of Gadara, which was an important urban and cultural center by the Hellenistic period. ${ }^{26}$ The discovery of a dedicatory inscription to Antoninus Pius, provides evidence for the laying of foundations in the second century $\mathrm{AD} .{ }^{27}$ The baths were in use until approximately AD 749 when an earthquake destroyed several cities in the Jordan valley. ${ }^{28}$

The analysis presented here will only look at evidence from the first Roman phase to determine if there are any similarities with the bathing custom in Rome as portrayed by the literary sources discussed above. First, there will be a discussion on the architecture, primarily to explain how the excavators assigned function to the various rooms in the complex. This discussion will not include particulars pertaining to construction technique, heating methods or water supply except where the excavators use this evidence to de-

\footnotetext{
${ }^{24}$ Tania Coen Uzzielli, "Marble Decorations, Wall Mosaics and Small Finds," in The Roman Baths of Hammat Gader, ed. Yizhar Hirschfeld (Jerusalem: Israel Exploration Society, 1997).

${ }^{25}$ Yizhar Hirschfeld, The Roman Baths of Hammat Gader: Final Report (Jerusalem: The Israel Exploration Society, 1997), 1.

${ }^{26}$ Hirschfeld, The Roman Baths of Hammat Gader, 4.

${ }^{27}$ Ibid.

${ }^{28}$ Ibid., 6.
} 
termine room function. Then the artefact assemblage will be examined to determine if there is a correlation between the architectural remains and the material evidence in determining room function.

The bath complex, as excavated, is comprised of nine labelled rooms (see Figure 1). The labels assigned to the various rooms are as follows: Area A, the Oval $\mathrm{Hall}^{29}$; Area B, the Passage Rooms $^{30}$; Area C, the Hall of Piers ${ }^{31}$; Area D, the Hall of Fountains $^{32}$; Area E, the Hall of Inscriptions ${ }^{33}$; Area F, the Service Area ${ }^{34}$; Area G, the Hot Spring Hall ${ }^{35}$; Area H, Entrance Corridor; ${ }^{36}$ Area J, the function and overall nature unclear at time of publication. ${ }^{37}$ I will exclude Area $\mathrm{J}$ from this study, as there was no significant material evidence excavated from it as well as Area F for, as its name implies, it was a service area not accessed by the bathers themselves. I will refer to the rooms by Area, rather than name, in the body of this paper.

Area $\mathrm{H}$ was accessed from the street and entered onto three of the rooms, Areas D, E and C. ${ }^{38}$ There does not appear to be a change room directly associated with Area $\mathrm{H}$, and the excavators hypothesize that the rooms located to the north were shops. The excavators suggest that the route used by the bathers began in Area C. ${ }^{39}$

\footnotetext{
${ }^{29}$ Ibid., 83-94.

${ }^{30}$ Ibid., $79-83$.

${ }^{31}$ Ibid., $62-73$

32 Ibid., 102-116.

${ }^{33}$ Ibid., $72-79$.

${ }^{34}$ Ibid., 119-123.

${ }^{35}$ Ibid., $94-102$.

${ }^{36}$ Hirschfeld, The Roman Baths of Hammat Gader, 54-62.

${ }^{37}$ Ibid., 116-119. Area J was not fully excavated at the time of publication but it has been conjectured that it may have been the palestrum.

${ }^{38}$ According to the excavation publication, the Entrance Corridor does not provide access to Area D. The plan, however, suggests otherwise, as there are steps leading from the Entrance Corridor down to Area D.

${ }^{39}$ See Figure 1 and the arrows indicating the conjecture progression of bathers through the complex.
} 
The bathers entered from the north, which has a monumental entrance. Based on evidence from underground pipes, the excavators believe that the room functioned as a frigidarium. ${ }^{40}$ Area Based on inscriptional evidence Area $\mathrm{C}$ is also believed to have been used for sporting activities. ${ }^{41}$

${ }^{40}$ Hirschfeld, The Roman Baths of Hammat Gader, 68-70.

${ }^{41}$ Ibid., 165.

For Inscription No. 1 see Hirschfeld 186-188. The inscription reads as follows: MHKETITAPBOCEXOITE_OETPO_OPOYACAMIN_OY

OY_OMENHCHMYPIA_O_OICA_EE_HKEN

.N_PACCINOMENHKTEINOYCATE_O_AKI_AI_AC

4.......C_APY_EP_ENO_HNKATEX_CATO_AI

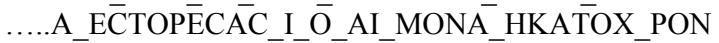

N........I_OYCTEP_IMBPOTONE_KEMENY_P

Be no longer in dread of the water-carrying bath being smashed, which brought infinite sorrows to many,

By hurting and killing men, in many cases children,

For the [yawning] earth buried it all from above.

But now, having laid a pavement [on either side], made a sporting place

Nikas (?), having let pleasant water to be drawn elsewhere.

Past Imperfect

13 (2007) | @ | ISSN 1192-1315 


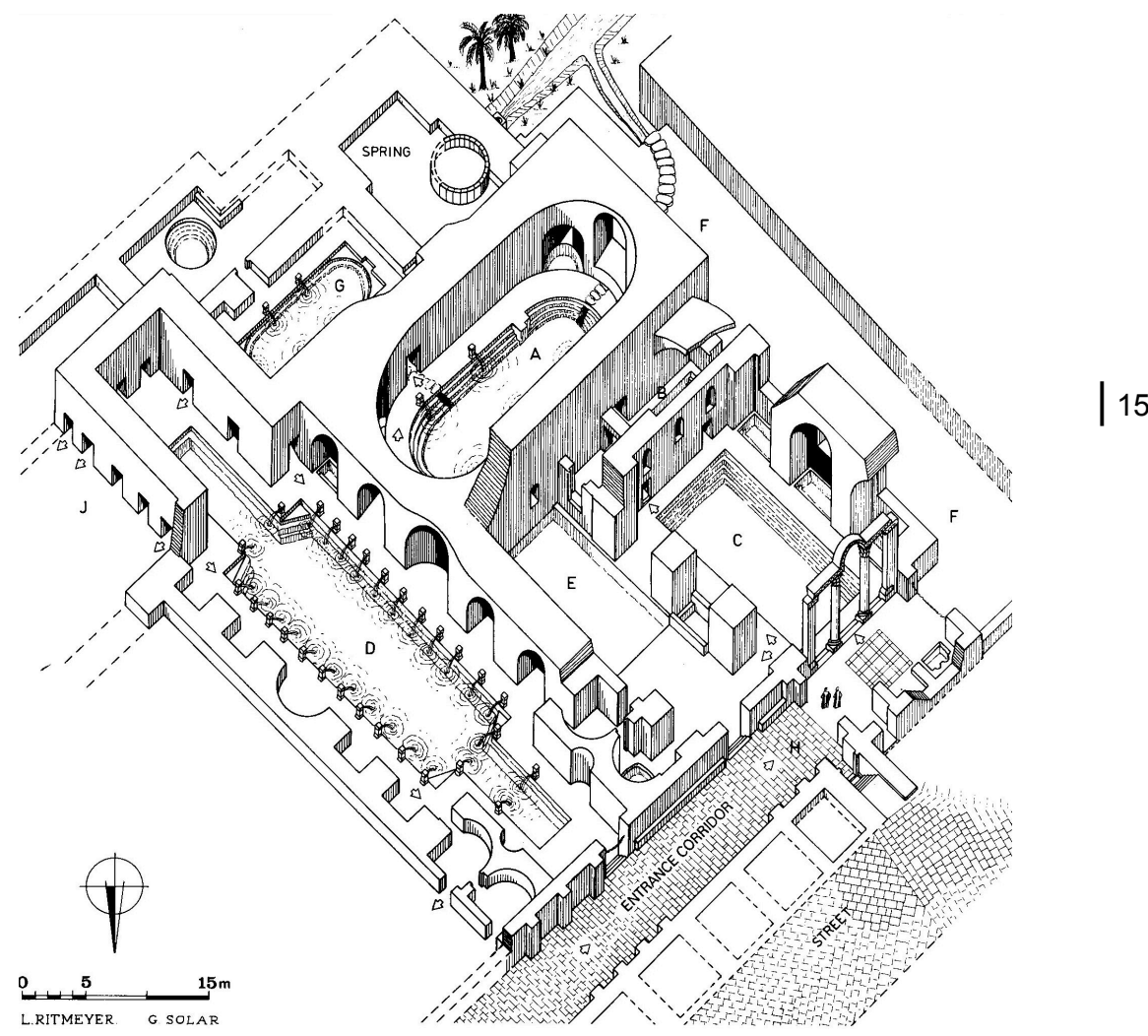

Figure from Hirschfeld, p. 55 Figure 51

Figure 1 - Partial Reconstruction of the baths complex

Area $\mathrm{E}$ is accessed from Area $\mathrm{C}$ and Area H. It is hypothesized that the main entrance was from Area $\mathrm{H}$ as there is more sign of wear on the stones, ${ }^{42}$ yet the arrows on Figure 1 indicate that the bathing route, as conjectured by the excavators, began in Area C. There is no specific function such as frigidarium, or tepidarium, or caldarium assigned to Area $\mathrm{C}$.

${ }^{42}$ Hirschfeld, The Roman Baths of Hammat Gader, 74.

Past Imperfect

13 (2007) | @ | ISSN 1192-1315 
Area B connects Areas C and A and is smaller in comparison. It consists of two rooms, the western one with a pool. There is no evidence of pipes leading into the pool. ${ }^{43}$ Area $\mathrm{B}$ is believed to have functioned as a tepidarium because of its low, narrow passage area. ${ }^{44}$ Area A is accessed from Area B and Area G. The pool, fed by the hot spring, ${ }^{45}$ is believed to have functioned as the caldarium. ${ }^{46}$

Area G, considered the "heart of the baths complex," comprised of three architectural units; one over the source of the spring, a large hall to the east of it, and a smaller room south of the large hall. Each unit had its own pool. ${ }^{48}$ Area D is the largest bathing hall in the complex and is centrally located. Area D is believed to have been the tepidarium. ${ }^{49}$

There is no other information provided in the publication of the excavation concerning room function. Assigning names such as frigidarium, tepidarium and caldarium is believed to imply room function as the literary sources outline various activities that took place in each of the rooms. I will now examine the artefact assemblage to determine if there is a correlation between the two.

The material evidence that I will consider in determining room function is the small finds. pottery and coins (See Tables 1 and 2). There is a section discussing the glass finds, but it does not adequately provide the locus of the finds to be applied. ${ }^{50}$ As the site was in use for a period of approximately 600 years there is a range of

\footnotetext{
${ }^{43}$ Hirschfeld, The Roman Baths of Hammat Gader, 82-83.

44 Ibid., 171.

${ }^{45}$ Ibid., 92.

${ }^{46}$ Ibid., 171.

${ }^{47}$ Ibid., 94.

${ }^{48}$ Ibid., 94.

${ }^{49}$ Ibid., 165

${ }^{50}$ Einat Cohen, "Roman, Byzantine and Umayyad Glass," in The Roman Baths of Hammat Gader, ed. Yizhar Hirschfeld (Jerusalem: The Israel Exploration Society, 1997).
} 
pottery from the second century to the eighth century A.D. ${ }^{51}$ The assemblage of pottery was found in a fill under a Byzantine floor in Areas B, C and E. I will discuss for the purpose of the argument presented here only the earlier pottery, associated with the first Roman phase. The types of pottery found were Galilean bowls, ${ }^{52}$ basins, ${ }^{53}$ cooking pots and casseroles, ${ }^{54}$ storage jars, pipes and amphorae, ${ }^{55}$ jugs, juglets, and bottles. The significance of these finds, is that this is one of the only published excavation report on baths that includes the finds including their provenance. ${ }^{56}$ This evidence provides further insight into what activities took place within the various rooms.

Area $\mathrm{H}$, identified as the entrance corridor according to the architecture does not appear to have had any other function based on the artefact assemblage. There were only coins recovered from this area. This supports the identification based on the architecture, as an entrance corridor is a locus of passage from one area to the next. People do not congregate in passageways but flow through them and as a result, there are no other functions associated with this space.

The excavators identified area $\mathrm{C}$ as a frigidarium. The artefact assemblage suggests that the room had more than one function. The presence of cooking pots, bowls and a spoon suggest that food was cooked and consumed in the area. It can be conjectured, by the large number of coins from this area, that bathers in this room purchased food. There were also two gaming pieces, which suggest that

${ }^{51}$ Roni Ben-Arieh, "The Roman, Byzantine and Umayyad Pottery," in The Roman Baths of Hammat Gader, ed. Yizhar Hirschfeld (Jerusalem: The Israel Exploration Society, 1997), 357.

${ }^{52}$ Ibid., 348-350.

${ }^{53}$ Ibid., 350-351.

${ }^{54}$ Ibid., 351-353.

${ }^{55}$ Ibid., 353-356.

${ }^{56}$ One exception to this is the baths at Caerleon, where the drains where excavated and the material from the drains analyzed. See Zienkiewicz, The Legionary Fortress Baths at Caerleon. 
gambling of some sort took place in this room. This also helps to explain the large number of coins.

Area $\mathrm{E}$ did not receive a specific function from the excavators, yet the artefact assemblage suggests that it was a multifunctional space. The cooking pots, bowls and knives suggest that the consumption of food occurred in this space. The spindle whorl suggests that women may have performed domestic tasks while utilizing the baths complex. The jewellery found in Area E supports the idea that women frequented this area. The number of artefacts associated with women in Area E, the fact that it had its own entrance from Area $\mathrm{H}$ and its lateral position to Area $\mathrm{C}$ suggests that maybe it also functioned as a caldarium but specifically for the use of women. Both Areas $\mathrm{C}$ and $\mathrm{E}$ are accessible from Area $\mathrm{H}$ and provide access to Area B. This suggests that there may have been division of space based on gender in the complex as they provide two separate entrances to the bath complex from the main entrance corridor.

Area $\mathrm{B}$, identified as the tepidarium is a smaller area in regards to the surrounding rooms but still produced an assemblage comparable to other areas. The buttons found in Area B are the only evidence suggesting that the apodyterium may have been located in the Area or at least the vicinity. At the very least, the room contained some kind of function, which required adjustment of clothing.

Area A, identified as the caldarium does not have a large assemblage, and hence I will not conduct any further analysis on it. Area $\mathrm{G}$, also believed to be a caldarium, has a small assemblage as well. This suggests two things; either that the caldaria were not multi-functional areas or that the debris from this room may have been washed away by a drain. The intense heat in these areas, as implied by the ancient terminology applied to this room, would not be 
conducive to a wide range of activities. ${ }^{57}$ Area D's artefact assemblage includes only jewellery and hence cannot give an accurate portrayal of its function based only on its artefact assemblage.

The excavation report on Hammat Gader details the architecture but does not fully consider the function of the various rooms. There is a section on the proposed reconstruction and the functions of the rooms but it provides little information in regards to function. By examining not only the architecture but also the artefact assemblage it is possible to move away from the standard assigned function as prescribed by ancient literary sources and arrive at a more comprehensive idea of what activities occurred in Roman baths.

\section{Conclusion}

This study has only considered one site. The results cannot explain how other Roman baths geographically and temporally separate from Hammat Gader functioned. What I would like to know is how this evidence compares to other bath complexes in Israel? How does the room function of this site compare to the evidence from Rome? Is there a distinguishable pattern of room use that is specific to Israel? Or, is the use specific to the time period? Was there a change in room function from when the Roman bathing habit first began to spread, in the late first century $\mathrm{BC}$ to early first century $\mathrm{AD}$, to the construction of the Hammat Gader complex in the second century $\mathrm{AD}$ ?

I hope that this study demonstrates that there is a need to continually use alternate modes of viewing to understand how the

${ }^{57}$ See Nielsen, Thermae et Balnea 1:17-18 for a discussion on how the hypocaust system functioned and the temperatures that could be achieved with this system, up to $80^{\circ} \mathrm{C}$. 
baths actually functioned. The literary evidence is only one means by which we can arrive at this understanding. I would like to see the discipline move towards regional studies of bathing practices. Although the baths, as a social entity, were a Roman invention, how the various cultures under Roman rule actually used them, that is what specific activities did they perform in the baths, could provide us 20 with a greater understanding of baths throughout the Roman world. For, can we say with any certainty that the bathing experience was consistent across the Roman world? 


\begin{tabular}{|c|c|c|}
\hline Bone and Clay Objects & & Locus \\
\hline Pins (5) & $\begin{array}{l}\text { Area } \mathrm{E}(2) \\
\text { Area } \mathrm{F} \\
\text { Area B } \\
\text { Area C }\end{array}$ & $\begin{array}{l}506 \text { - Above the stone covering of L. } 505 \\
\text { (505 = Late channel from Area A) } \\
621 \text { - Drainage channel of Area B, joins } \\
\text { channel of L. } 613 \text { (Excavation of the } \\
\text { main drainage channel opposite the } \\
\text { entrance to Area B } \\
213 \text { - Eastern room, beneath the pavement } \\
\text { of L. } 207 \text { [Eastern room, beneath the } \\
\text { stone floor of L. } 205 \text { (Eastern room, } \\
\text { beneath L. 204) } 204 \text { - Eastern room, } \\
\text { from the surface to the late earthen } \\
\text { floor] } \\
302 \text { - North of the columned portal, above } \\
\text { the basalt floor }\end{array}$ \\
\hline Gaming Pieces (2) & $\begin{array}{l}\text { Area C } \\
\text { Area C }\end{array}$ & $\begin{array}{l}324 \text { - Middle bathtub in the western row of } \\
\text { W6, above the floor } \\
314 \text { - Penetrating the marble floor of L. } 311 \\
\text { (Central cell behind W27, above the } \\
\text { floor) }\end{array}$ \\
\hline Buttons (4) & $\begin{array}{l}\text { Area B (3) } \\
\text { Area B }\end{array}$ & $\begin{array}{l}205 \text { - Eastern room, beneath L. } 204 \text { (East- } \\
\text { ern room, from the surface to the late } \\
\text { earthen floor) } \\
211 \text { - Pool in western room, beneath the } \\
\text { pavement of L. } 201\end{array}$ \\
\hline Spindle Whorls (3) & $\begin{array}{l}\text { Area B } \\
\text { Area E } \\
\text { Area B }\end{array}$ & $\begin{array}{l}200 \text { - Western room, from the surface to the } \\
\text { late stone floor } \\
516 \text { - Central pool beneath the floor of } \\
\text { inscriptions } \\
201 \text { - Western room, beneath the floor of L. } \\
200 \text { (see above) }\end{array}$ \\
\hline $\begin{array}{l}\text { Perorated Clay } \\
\text { Discs (3) }\end{array}$ & Area A (2) & $\begin{array}{l}213 \text { - Eastern room, beneath the pavement } \\
\text { of L. } 207 \text { (Eastern room, beneath the } \\
\text { stone floor of L. } 205 \text { (Eastern room, } \\
\text { beneath L. } 204 \text { (Eastern room, from } \\
\text { the surface to the late earthen floor) } \\
101 \text { - From the surface at the eastern end of } \\
\text { the hall to the basalt pavement }\end{array}$ \\
\hline \multicolumn{3}{|l|}{ Metal Objects } \\
\hline Hook (1) & Area $\mathrm{E}$ & $\begin{array}{l}523 \text { - Above the floor of inscriptions at the } \\
\text { northern end of the area (continuation } \\
\text { of L. } 510 \text { ) - L. } 510=\text { Excavation } \\
\text { above the floor of inscriptions (con- } \\
\text { tinuation of L. } 500 \text { and } 501) 500= \\
\text { from the surface to the plaster floor, at } \\
\text { southern end of area (= L. 209) } 209= \\
\text { Area E (= L. 500) } 501=\text { Continuation } \\
\text { of L. } 500 \text { in the center of the area (= } \\
\text { L. 212) } 212=\text { Moved to Area E (= L. }\end{array}$ \\
\hline
\end{tabular}




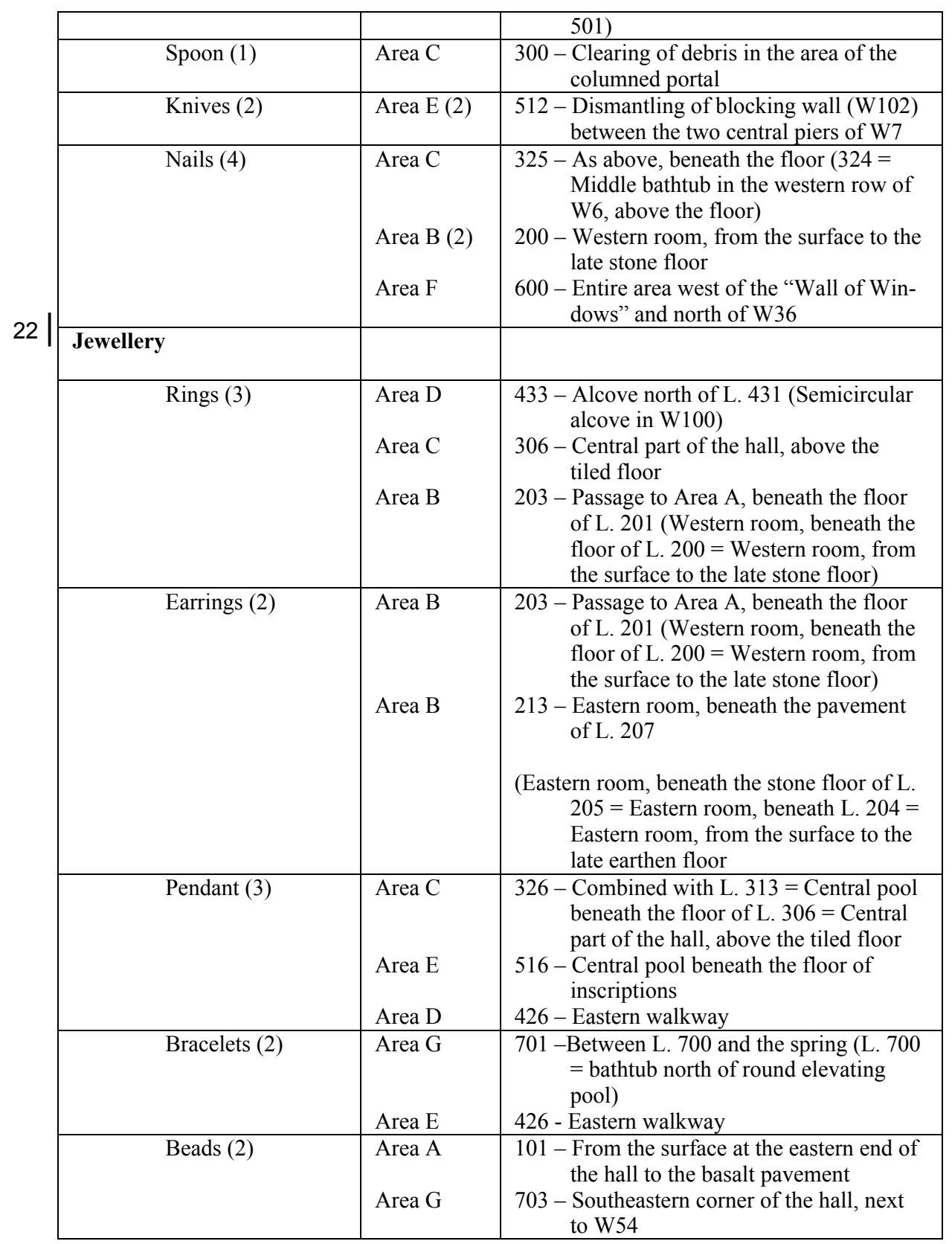

Table 1 - Small Finds

Past Imperfect

13 (2007) | @ | ISSN 1192-1315 


\begin{tabular}{|l|l|}
\hline \multicolumn{1}{|c|}{ Area } & \multicolumn{1}{|c|}{ Artefact Assemblage } \\
\hline Area A & Bead \\
& Clay disc \\
& Spoon \\
\hline Area B & Basins (5) \\
& Bowls (2) \\
& Buttons (4) \\
& Coins (16) \\
& Cooking Pots (4) \\
& Clay disc \\
& Earrings (2) \\
& Lamps (1) \\
& Nail \\
& Pin \\
& Ring \\
& Spindle whorls (2) \\
\hline Area C & Basins (9) \\
& Bowls (3) \\
& Coins (109) \\
& Cooking Pots (14) \\
& Gaming pieces (2) \\
& Nail \\
& Pendant \\
& Pin \\
& Ring \\
& Spoon \\
\hline Area D & Ring \\
& Pendant \\
\hline Area E & Basins (6) \\
& Bowls (18) \\
& Bracelet \\
& Coins (12) \\
& Cooking Pots (17) \\
\hline Area G & Hook \\
& Knives (2) \\
& Pendant \\
& Pins (2) \\
& Spindle whorl \\
\hline & Bead \\
& Bracelet \\
\hline & Coins (33) \\
& \\
\hline
\end{tabular}

Table 2 - Artefact Assemblage by Area

Past Imperfect

13 (2007) | @ | ISSN 1192-1315 